\title{
PSYCHOSOCIAL IMPLICATIONS OF PRENATAL TELEHEALTH GENETIC COUNSELLING: A SYSTEMATIC REVIEW
}

\author{
Lauren A Beretich MS, LCGC ${ }^{1}$, Jane M DeLuca PhD, RN, CPNP ${ }^{1,2}$, Julia A Eggert PhD, AGN-BC, FAAN ${ }^{1}$ \\ ${ }^{1}$ School of Nursing, Clemson University, Clemson, South Carolina, USA \\ ${ }^{2}$ The Greenwood Genetic Center, Greenwood, South Carolina, USA
}

\begin{abstract}
Introduction: Telehealth is a growing service delivery model in clinical genetics and genetic counselling. Despite its popularity, telehealth genetic counselling (TGC) is often not incorporated into prenatal genetic services. Methods: A literature review was conducted to identify peer-reviewed, original research articles, which examined the psychosocial implications (e.g. satisfaction) of prenatal TGC. Using the PubMed database, searches were conducted using the following key terms: "Telehealth Genetic Counselling", "Prenatal Genetics Telehealth" and "Telegenetics". Results: The search returned 82 articles; only five articles assessed the psychosocial implications of prenatal TGC. The TGC delivery methods varied among studies, but results consistently revealed positive responses, most notably patient satisfaction. Conclusions: Further use and research of TGC are needed to better understand the social implications of this service delivery model for prenatal populations. This information is essential to guide clinical care for prenatal populations.
\end{abstract}

Keywords: telehealth; telegenetics; genetic counselling; perinatal genetic counselling

Beritich LA, et al. JISfTeH 2018;6:e21(1-6).

DOI: https://doi.org/10.29086/JISfTeH.6.e21

Crossref

Open access, published under Creative Commons Attribution 4.0 BY International Licence

\section{Introduction}

Genetic counselling is a dynamic profession, defined by the National Society of Genetic Counselors as "the process of helping people understand and adapt to the medical, psychological and familial implications of genetic contributions to disease." ${ }^{\prime 1}$ The profession incorporates a process older than the clinical practice itself, as historically, physicians provided genetic counselling to patients. ${ }^{2-4}$ For the purpose of this review, genetic counsellors are defined as practitioners who are educated at the master's degree level. While some genetic counsellors practice within multiple specialties, many work with targeted populations. ${ }^{5}$

A prenatal genetic counsellor works, at least in part, with an obstetric population. Approximately $41 \%$ of practicing genetic counsellors in the United States and Canada work in a prenatal setting according to the 2018 National Society of Genetic Counselors (NSGC) Professional Status Survey (PSS). ${ }^{5}$ Genetic counsellors who counsel patients practice most often within a university medical centre (39\%), public hospital/medical facility (24\%), or a private hospital/medical facility $(21 \%) .{ }^{5}$ These statistics are anticipated to reflect prenatal genetic counsellors' practice settings.

Primary providers in obstetrics and reproductive endocrinology specialists largely generate referrals for prenatal genetic counselling. Common indications for refer- ral include: 1) advanced maternal age (women 35 years of age or older at delivery with a singleton gestation), 2) abnormal screening for aneuploidy (maternal serum or cellfree DNA), 3) abnormal prenatal ultrasound, 4) genetic carrier status and 5) family history of birth defects or genetic disease. ${ }^{6}$ While it is acknowledged that prenatal genetic counsellors also counsel families prior to conception, in the context of this review, prenatal genetic counselling occurs during a clinically recognised, ongoing pregnancy.

The World Health Organization (WHO) uses the terms telehealth and telemedicine interchangeably and defines these as, "the delivery of health care services, where distance is a critical factor, by all health care professionals using information and communication technologies for the exchange of valid information for diagnosis, treatment and prevention of disease and injuries, research and evaluation, and for the continuing education of health care providers, all in the interests of advancing the health of individuals and their communities." Telehealth has expanded since its inception in the 1960s and has been adopted by a number of medical specialties including, but not limited to radiology, pathology and dermatology. ${ }^{8-9}$

The specific form of telehealth, telegenetics, is a term used to describe genetic services provided by healthcare professionals with genetics training and expertise. These providers may include physicians, genetic counsellors, 
nurses or dietitians. This service delivery model is generally synchronous, with information transmitted from healthcare provider to patient. Common modalities include telephone or videoconferencing. ${ }^{10-12}$ Telegenetics has been traditionally used to reach patients in rural areas with limited access to healthcare services. ${ }^{12-13}$ In this review, the term telehealth genetic counselling (TGC) is used to describe the genetic counselling process provided by a genetic counsellor.

While TGC is currently being used, this service delivery model in the prenatal setting is limited and based on colloquial knowledge. Available research has demonstrated specific specialties have a greater use of TGC, most notably cancer genetics. ${ }^{14-16}$ The cause of this discrepancy in use is currently unclear. Thus, a systematic review of the literature was conducted to 1) objectively identify current literature surrounding TGC for prenatal indications and 2) specifically review and compare the identified psychosocial implications.

\section{Methods}

Literature for this review was systematically selected. The search was initially completed in May of 2017 and repeated in June of 2018 in an attempt to include additional eligible studies published between May of 2017 and June of 2018. Details from only the 2018 search are included below. However, no additional articles meeting inclusion criteria were identified in the 2018 search.

Using PubMed, the key terms "Telehealth Genetic Counseling", "Prenatal Genetics Telehealth" and "Telegenetics" were used. PubMed is a comprehensive database that includes literature from MEDLINE, many life science journals and online book sources. ${ }^{17}$ This search was not limited by date, as TGC is a modern service delivery model. Peer-reviewed, original research that assessed the psychosocial implications of TGC and used a prenatal population was included. Articles that did not meet the above criteria were excluded. The described query returned a total of 82 results.

Of those, 27 duplicate results were excluded. A total of 15 results were not related to the field of genetic counselling and were excluded. Non-original research studies (11), studies not assessing the psychosocial implications following TGC (14) and studies not using a prenatal population (12) were also excluded. The reference lists of the remaining three articles were reviewed. Two additional articles met inclusion criteria and were also included in this review.

\section{Results and Discussion}

Five articles assessed the psychosocial implications of TGC for prenatal indications and are detailed in Table 1. ${ }^{18-22}$ Each article had a unique focus. Sangha et al. determined the differences in patients' understanding and anxiety when genetic counselling for a positive triple screen was conducted in person versus over the telephone. ${ }^{18}$ The study by Lea et al. aimed to increase access to genetic services in Maine. ${ }^{19}$ Hunter et al. compared the effectiveness of individual, group and use of a decision aid in prenatal diagnosis counselling for women of advanced maternal age and their partners. ${ }^{20}$ The study by Abrams and Geier compared patient satisfaction of prenatal genetic counselling performed via videoconferencing versus on-site. ${ }^{21}$ Lastly, Otten et al. evaluated the practical aspects, satisfaction and psychological outcomes of online genetic counselling taking place as part of a pilot study. ${ }^{22}$

\section{Study Participants and TGC Modality}

Participants were from the United States (2), Canada (2) and the Netherlands (1). ${ }^{18-22}$ Of importance, only three studies used an entirely prenatal sample, including 7 females, 24 females and 577 male and female participants. ${ }^{18,20,21}$ Two studies used a limited prenatal sample. ${ }^{19,22}$ Otten et al. provided prenatal TGC for 3 males and 3 females out of 57 total participants. ${ }^{22}$ Lea et al. provided prenatal TGC for 3 females out of 105 total individuals. In this study 26 participants completed satisfaction surveys; it was not reported if any of these individuals received prenatal TGC. ${ }^{19}$ Another difference among studies was the modality of TGC. Sangha et al. used telephone counselling, Hunter et al, used an audiovisual decision aid, and the remaining studies used videoconferencing. ${ }^{18-22}$

\section{Satisfaction}

Participant satisfaction after TGC was consistently perceived as positive and quantitatively measured in all five studies. ${ }^{18-22}$ These studies used a Likert scale to measure participant satisfaction. Lea et al. used a 4-point scale. Participants reported an average satisfaction score of 3.6 out of $4 .{ }^{19}$ Abrams and Grier used and 5-point scale; participants reported an average score between 4 and 5 out of 5 to questions assessing satisfaction; a more specific numeric value was not provided. ${ }^{21}$ Sangha et al. assessed participant satisfaction through their written questionnaire to assess anxiety, using the question, "I feel satisfied with the genetic counselling session that I received, and I feel that all my questions were answered." A 5-point Likert scale was used, and participants indicated a score of 0.6 out of 4 on average, where 0 indicates "strongly agree." 18

Other research groups used a more complex system to measure participant satisfaction. Hunter et al. used the intervention satisfaction questionnaire (ISQ). ${ }^{20}$ The ISQ is a validated 11-item short form derived from the 32-item satisfaction with genetic counselling scale. The benefit of the ISQ is it has shown consistent validity and is specifically tailored to assess genetic counselling satisfaction. ${ }^{23}$ Participants reported an average score of 37.3 for women and 36.0 points for men out of a total of 44 , consistent with a high level of satisfaction. ${ }^{20}$ Otten et al. used the Clinical Genetics Satisfaction (CGS) indicator to assess satisfaction with counselling/content as well as the Telemedicine Satisfaction Questionnaire (TSQ) to assess telemedicine satisfaction. ${ }^{22}$ The 7-point CGS indicator has shown internal consistency 
Table 1. Characteristics of included articles in this systematic review.

\begin{tabular}{|c|c|c|c|c|c|c|}
\hline Studies & \multicolumn{2}{|c|}{ Participants } & \multicolumn{2}{|c|}{ Evaluation } & \multicolumn{2}{|c|}{ Results } \\
\hline $\begin{array}{c}\text { First Author } \\
\text { (Year) } \\
\text { Country }\end{array}$ & $\begin{array}{l}\text { Indication(s) } \\
\text { for Genetic } \\
\text { Counselling }\end{array}$ & $\begin{array}{c}\text { Included in } \\
\text { Analysis }\end{array}$ & Satisfaction & Anxiety & $\begin{array}{c}\text { Satisfaction } \\
\text { (Satisfied/Not } \\
\text { Satisfied) }\end{array}$ & $\begin{array}{c}\text { Anxiety } \\
\text { (Increased/ } \\
\text { Decreased) }\end{array}$ \\
\hline $\begin{array}{c}\text { Sangha }^{18} \\
(2003) \\
\text { Canada }\end{array}$ & $\begin{array}{l}\text { Positive triple } \\
\text { screen for } \\
\text { Down } \\
\text { syndrome }\end{array}$ & $\begin{array}{c}\mathrm{N}=24 \\
\text { Clinic visit group } \\
(\mathrm{n}=12) \\
\text { Telephone group } \\
(\mathrm{n}=12)\end{array}$ & $\begin{array}{l}\text { Question, "I } \\
\text { feel satisfied } \\
\text { with the genetic } \\
\text { counselling } \\
\text { session that I } \\
\text { received, and I } \\
\text { feel that all my } \\
\text { questions were } \\
\text { answered." }\end{array}$ & $\begin{array}{l}\text { Pre- and post- } \\
\text { counselling } \\
\text { anxiety } \\
\text { questionnaires }\end{array}$ & Satisfied & Decreased \\
\hline $\begin{array}{c}\text { Hunter }^{20} \\
(2005) \\
\text { Canada }\end{array}$ & $\begin{array}{c}\text { Advanced } \\
\text { maternal age }\end{array}$ & $\begin{array}{c}\mathrm{N}=577 \\
\text { Randomised to } \\
\text { the individual } \\
\text { counselling, } \\
\text { group } \\
\text { counselling, or } \\
\text { decision aid } \\
\text { group }\end{array}$ & $\begin{array}{c}\text { Intervention } \\
\text { Satisfaction } \\
\text { Questionnaire } \\
\text { (ISQ) }\end{array}$ & $\begin{array}{c}\text { Traditional } \\
\text { State and Trait } \\
\text { Anxiety } \\
\text { Inventory } \\
\text { (STAI) }\end{array}$ & Satisfied & Decreased \\
\hline $\begin{array}{c}\text { Lea }^{19} \\
(2005) \\
\text { United States }\end{array}$ & $\begin{array}{l}\text { Paediatric, adult } \\
\text { and } \\
\text { reproductive }^{\mathrm{a}}\end{array}$ & $\begin{array}{c}\mathrm{N}=26 \\
\text { A total of } 105 \\
\text { participants } \\
\text { (including } 3 \\
\text { prenatal) were } \\
\text { surveyed with a } \\
\text { 25\% response } \\
\text { rate }\end{array}$ & $\begin{array}{c}\text { Patient } \\
\text { Satisfaction } \\
\text { Evaluation } \\
\text { Form }\end{array}$ & $\mathrm{NA}$ & Satisfied & NA \\
\hline $\begin{array}{c}\text { Abrams }^{21} \\
(2006) \\
\text { United States }\end{array}$ & $\begin{array}{c}\text { Abnormal } \\
\text { maternal serum } \\
\text { screening and } \\
\text { advanced } \\
\text { maternal age }\end{array}$ & $\begin{array}{c}\mathrm{N}=80 \\
\text { Counselled on- } \\
\text { site }(\mathrm{n}=73) \\
\text { Counselled by } \\
\text { video- } \\
\text { conferencing } \\
(\mathrm{n}=7)\end{array}$ & $\begin{array}{l}\text { Survey created } \\
\text { to assess } \\
\text { satisfaction } \\
\text { with the genetic } \\
\text { counselling } \\
\text { experience }\end{array}$ & NA & Satisfied & NA \\
\hline $\begin{array}{c}\text { Otten }^{22} \\
(2016) \\
\text { Netherlands }\end{array}$ & $\begin{array}{l}\text { Presymptomatic } \\
\text { cardiogenetic, } \\
\text { presymptomatic } \\
\text { oncogenetic } \\
\text { and prenatal }^{\mathrm{b}}\end{array}$ & $\begin{array}{c}\mathrm{N}=128 \\
\text { Prenatal online } \\
\text { counselling } \\
(\mathrm{n}=6) \\
\text { Prenatal } \\
\text { conventional } \\
\text { counselling } \\
(\mathrm{n}=10)\end{array}$ & $\begin{array}{c}\text { Clinical } \\
\text { Genetics } \\
\text { Satisfaction } \\
\quad(\mathrm{CGS}) \\
\text { Indicator and } \\
\text { Telemedicine } \\
\text { Satisfaction } \\
\text { Questionnaire } \\
\text { (TSQ) }\end{array}$ & $\begin{array}{c}\text { Abbreviated } \\
\text { State and Trait } \\
\text { Anxiety } \\
\text { Inventory } \\
\text { (STAI) }\end{array}$ & Satisfied & Decreased \\
\hline
\end{tabular}

when used in clinical genetics; participants who received TGC had a CGS item score of 2.9 out of 5 on average, which was not significantly different from the control group. The TSQ is a validated 14-item questionnaire; following TGC, participants reported an average TSQ score of 4.5 out of 5 . these individuals were also significantly more satisfied postTGC than they had previously expected..$^{22}$

\section{Anxiety}

Anxiety levels in response to TGC were mixed and quantitatively evaluated in three studies. ${ }^{18,20,22}$ Sangha et al. 
found participants had decreased anxiety after TGC. The precounselling verbal anxiety survey consisted of two questions and a maximum score of 20. On average, participants reported a 14.5 out of $20(72.3 \%)$ prior to TGC. Postcounselling participants were provided a written questionnaire, which included an anxiety portion. This survey consisted of 10 questions and was adapted using questions from previous studies, some of which came from validated questionnaires. Five genetic counselling students reviewed this questionnaire to assess content and understandability. On average participants reported a score of 17.7 out of a maximum score of 40 (44.3\%). In both surveys a higher score was associated with a higher level of perceived anxiety. ${ }^{18}$ Anxiety scores appear to have dropped after TGC.

Hunter et al. and Otten et al. both used the State and Trait Anxiety Inventory (STAI) to assess anxiety. ${ }^{20,22}$ The STAI is a validated tool to measure anxiety and the tendency to be anxious; higher scores are associated with increased levels of anxiety. ${ }^{24}$ Hunter et al. used the traditional STAI, which includes both the state subscale (20 items) and the trait subscale (20 items). Participants who received TGC did not have a significantly reduced level in anxiety; scores were reduced from 46.7 to 45.5 (range 40-60). ${ }^{20}$ Alternatively, Otten et al. used an abbreviated, validated, Dutch version of the STAI, which was only six items. Again, participant anxiety was not significantly reduced following TGC. Participant STAI scores were reduced from 1.7 to 1.6 (range $1-4) .{ }^{22}$ Unfortunately, numeric results among these studies cannot be directly compared.

\section{Other Psychosocial Implications}

Three studies used written free-responses or telephone interviews to gather more information about the psychosocial implications of TGC. ${ }^{18,19,21}$ While all three studies allowed for written free responses, only Lea et al. also contacted participants for phone interviews. ${ }^{19}$ A participant who received telephone genetic counselling commented that her TGC was "as good as going in for an appointment." ${ }^{18}$ Lea et al. identified TGC participants repeatedly reported benefits, including savings of time and travel and convenient access. ${ }^{19}$ Alternatively, a participant who received TGC by videoconference reported, "it would have been nice to just have had the more personal experience." 21

\section{Limitations}

There are notable limitations to this systematic review. As described, only five studies met inclusion criteria using the described search. Only one database, PubMed, was used. Studies accessible elsewhere were not included.

Furthermore, the number of individuals who received TGC for a prenatal indication was limited in most studies ( $<25$ individuals) and only representative of a fraction of the total sample in two studies. ${ }^{18-22}$ Thus, it is unclear if results are generalisable to the broader prenatal population. Moreover, Lea et al. did not clearly state if any individuals seen for a prenatal indication completed a satisfaction survey. ${ }^{19}$ Lastly, some studies used an entirely female sample, while others included male partners, which may have altered the results. ${ }^{18-22}$

Each article reviewed was unique. First, the articles were published in 2003, 2005(2), 2006 and 2016. ${ }^{18-22}$ Due to this, it is unclear if results are representative of prenatal TGC from the current decade. One consideration is the introduction and rapid expansion of cell-free DNA screening. Of note, different modes of telehealth were used, most often videoconferencing. It is possible more sophisticated videoconferencing technology could correlate with higher levels of patient satisfaction. The influence of novel testing and improved technologies was not assessed in this review.

The indications for prenatal TGC also differed. Most commonly, participants were referred due to abnormal maternal serum screening or advanced maternal age. ${ }^{18,20,21}$ Lea et al. and Otten et al. did not report the indication(s) for prenatal TGC, which impairs any further interpretation. ${ }^{19,22}$ Overall, the psychosocial effect of the indication for prenatal genetic counselling could not be assessed by this review.

Additionally, data collection tools varied between studies. Validated survey instruments were not used in two studies. ${ }^{19,21}$ While Sangha et al. also did not use validated survey tools, questions used were adapted form previously published questionnaires, some of which had been validated. ${ }^{18}$ Lastly, both Hunter et al. and Otten et al. used validated and well-studied data collection tools for measuring patient satisfaction and anxiety. ${ }^{20,22}$

\section{Conclusion}

TGC is an emerging service delivery model for prenatal indications. Today, there is limited up-to-date literature on this topic. For this reason, practices and individual practitioners providing prenatal TGC are encouraged to publish their internal data and experiences that best reflect the current state of prenatal TGC.

This review has indicated that overall, patient satisfaction with TGC is positive, and patient anxiety may be reduced. Other perceived benefits, such as increased convenience, were reported. Validated data collection tools are essential for future research within and between research groups. Furthermore, defining and standardising psychosocial and other social implications is necessary to improve future telehealth research. Overall, further research is needed to better assess the social implications of prenatal TGC.

Lastly, considering this review, it is unreasonable to conclude negative psychosocial implications of prenatal TGC are the driving factor for its apparent limited use. Further research is needed to understand the perceived barriers to the incorporation of prenatal TGC. Furthermore, genetic counsellors caring for prenatal populations are encouraged to consider using TGC, not as a replacement, but as an adjunct to the traditional service delivery model. If the field fails to use and conduct research on prenatal TGC, an 
opportunity is missed to provide meaningful genetic counselling for prenatal populations.

\section{Corresponding author: \\ Lauren A. Beretich \\ clo J. DeLuca \\ 421 Edwards Hall, Box 159 \\ Clemson University \\ Clemson, SC 29634 \\ USA \\ Email: lbereti@clemson.edu}

Conflict of interest. The authors declare no conflicts of interest.

\section{References}

1. Resta R, Biesecker BB, Bennett RL et al. A new definition of genetic counseling: National society of genetic counselors' task force report. J Genet Counsel 2006;15(2):77-83.

2. Heimler A. An oral history of the national society of genetic counseling. J Genet Counsel 1997;6(3):315336.

3. Dice LR. A panel discussion: Genetic counseling. Am J Hum Genet 1952;4(4):332-346.

4. Sites J, Jacobson C. Genetic counseling in obstetrics and gynecology. Ann N Y Acad Sci 1967;142(3):768772.

5. National Society of Genetic Counselors. (2018). 2018 Professional status survey reports. Available at: http://www.nsgc.org/page/whoaregeneticcounselors accessed 10 June 2018.

6. Pletcher BA, Toriello HV, Noblin SJ et al. Indications for genetic referral: a guide for healthcare providers. Genet Med 2007;9(6):385-389.

7. World Health Organization. (1998). A health telematics policy in support of WHO's health-for-all strategy for global health development: Report of the WHO group consultation on health telematics, 11-16 Dec 1997. Geneva: World Health Organization.

8. Craig J, Patterson V. Introduction to the practice of telemedicine. J Telemed Telecare 2005;11(1):3-9.

9. World Health Organization. (2010). Telemedicine: opportunities and developments in member states. Available at: http://www.who.int/goe/publications/g oe telemedicine 2010.pdf accessed June 18, 2017.

10. Wenger TL, Gerdes J, Taub K et al. Telemedicine for genetic and neurologic evaluation in the neonatal intensive care unit. J Perinatol 2014;34(3):234-240.

11. Otten E, Birnie E, Lucassen AM, Ranchor AV, Van Langen IM. Telemedicine uptake among genetics professionals in Europe: room for expansion. Eur $J$ Hum Genet 2016;24(2):157-163.

12. Vrčar I, Hristovski D, Peterline B. Telegenetics: an update on availability and use of telemedicine in clinical genetics service. J Med Syst 2017;41(2):21.

13. Hilgart J, Hayward J, Coles B, Iredale R. Telegenetics: a systematic review of telemedicine in genetics services. Genet Med 2012;14(9):765-776.

14. Buchanan AH, Rahm AK, Williams JL. Alternate service delivery models in cancer genetic counseling: A mini-review. Front Oncol 2016;6:120.

15. Buchanan AH, Datta SK, Skinner CS et al. Randomized trial of telegenetics vs. in-person cancer genetic counseling: cost, patient satisfaction and attendance. J Genet Couns 2015;2(6):961-970.

16. McDonald E, Lamb A, Grillo B, Lucas L, Miesfeldt S. Acceptability of telemedicine and other cancer genetic counseling models of service delivery in geographically remote settings. J Genet Couns 2014;23(2):221-228.

17. National Center for Biotechnology Information (US). (2018). PubMed Help [Internet]. Available at: https://www.ncbi.nlm.nih.gov/books/NBK3827/ accessed 24 November 2018.

18. Sangha KK, Dircks A, Langlois S. Assessment of the effectiveness of genetic counseling by telephone compared to a clinic visit. J Genet Couns 2006;12(2):171-184.

19. Lea DH, Johnson JL, Ellingwood S et al. Telegenetics in Maine: Successful clinical and educational service delivery model developed from a 3-year pilot project. Genet Med 2005;7(1):21-27.

20. Hunter A, Cappelli M, Humphreys L et al. A randomized trail comparing alternative approaches to prenatal diagnosis counseling in advanced maternal age patients. Clin Genet 2005;67(4):303-313.

21. Abrams D, Geier M. A comparison of patient satisfaction with telehealth and on-site consultations: a pilot study for prenatal genetic counseling. J Genet Couns 2006;15(3):199-205.

22. Otten E, Birnie E, Ranchor AV, Van Langen IM. Telegenetics use in presymptomatic genetic counselling: patient evaluations on satisfaction and quality of care. Eur J Hum Genet 2016;24(4):513-520.

23. Shiloh S, Avdor O, Goodman RM. Satisfaction with genetic counseling: dimensions and measurement. Am J Med Genet 1990;37(4):522-529.

24. Julian LJ. Measures of anxiety: State-Trait Anxiety Inventory (STAI), Beck Anxiety Inventory (BAI), and Hospital Anxiety and Depression Scale-Anxiety (HADS-A). Arthritis Care Res (Hoboken) 2011;63(S11):S467-472. 